\title{
MELTING POINTS OF THE IRON GROUP ELEMENTS BY A NEW RADIATION METHOD.
}

\author{
By Geo. K. Burgess.
}

Recently ${ }^{1}$ Dr. Waidner and the author suggested two radiation methods for the determination of high melting points of substances in minute quantities. The first depends on the total radiation from a surface as measured in terms of some instrument making use of the Stefan-Bolzmann law. The second method is based on the measurement of the intensity of a particular monochromatic radiation from platinum or other substance; that is, it makes use of an instrument based on Wien's equation. ${ }^{2}$

Some preliminary measurements made at that time by the second method on the metals of the iron group showed it to possess considerable accuracy and to be particularly applicable to the easily oxidized elements if the melts were obtained in an atmosphere of pure hydrogen. It was also demonstrated that a compound of one of the refractory elements, which could be reduced to the metal by hydrogen, might serve as material for determining the melting point of the pure metal.

The present paper is an account of the application of this second method to the determination of the melting points in hydrogen of the members of the iron group, using, for the measurement of temperature a Holborn-Kurlbanm optical pyrometer, and the data on the monochromatic radiation from platinum published in this Bulletin. ${ }^{3}$

\footnotetext{
${ }^{1}$ Waidner and Burgess: On the Determination of Melting Points by Radiation Method, Phys. Rev., 22, p. 359; 1906.

${ }^{2} \mathrm{~A}$ discussion of the laws of radiation will be found in this Bulletin, 1, p. I89; 1905.

${ }^{3}$ Waidner and Burgess, this Bulletin, 3, p. I; 1907.
} 
Experimental Method.-The arrangement of the apparatus is shown in Fig. I, and is as follows: Within the blackened brass cylinder $\mathrm{C}$ is a strip of pure platinum $\mathrm{P}$, about $6 \mathrm{~cm}$ long, $4 \mathrm{~mm}$ wide, and $0.02 \mathrm{~mm}$ thick. This platinum strip is heated electrically to any desired temperature, and by means of a rheostat, which has a fine adjustment, very delicate control of the temperature of $\mathrm{P}$ is obtained. The cylinder $\mathrm{C}$ is connected to an electrolytic hydrogen generator in series witl an alkaline pyrogallate solution and a drv-

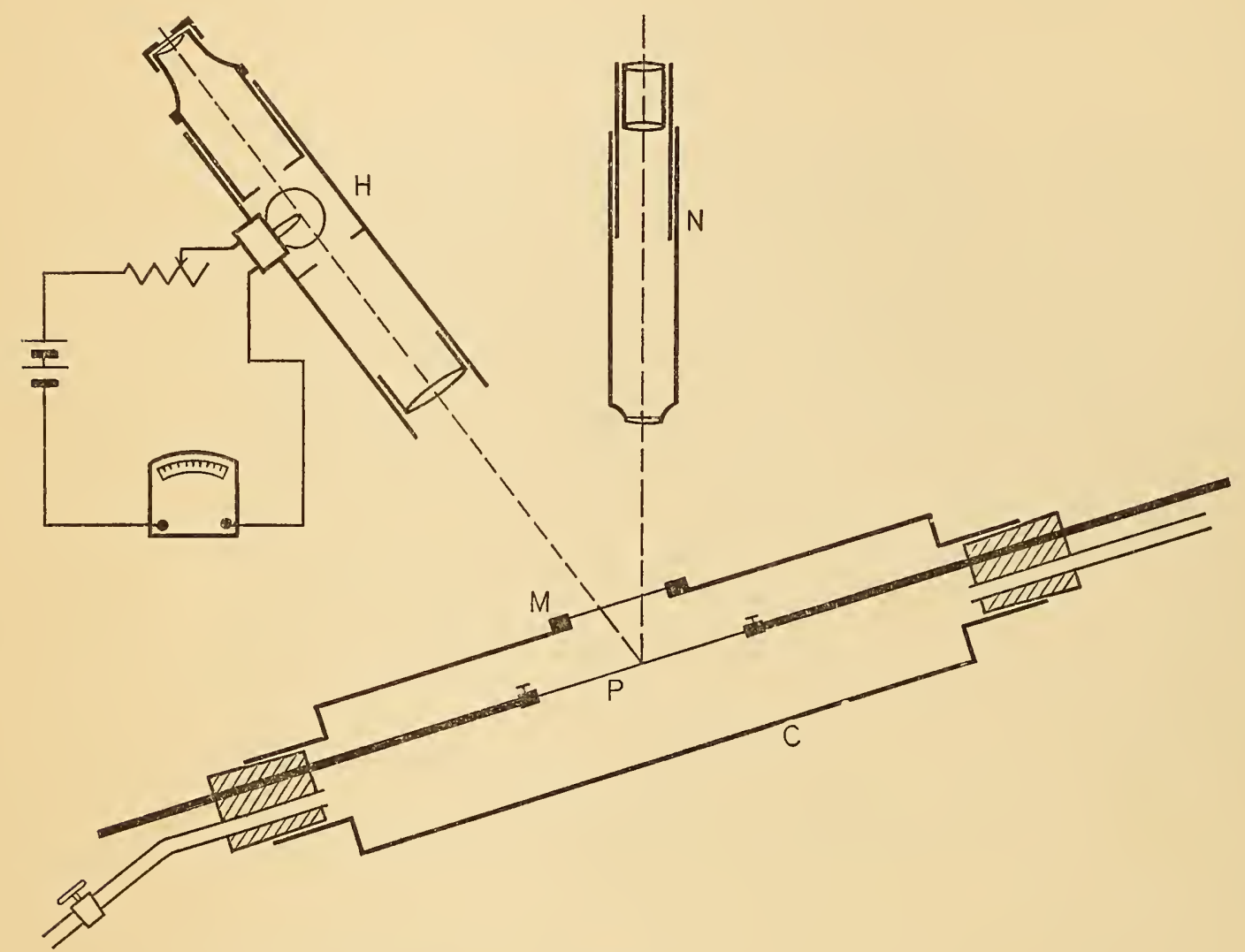

Fig. 1.

ing tube of calcium chloride. At $M$ is a removable window of thin mica, giving access to the cylinder and permitting observation of $\mathrm{P}$ both with the microscope $\mathrm{N}$ and the optical pyrometer $\mathrm{H}$.

To take an observation of a melting point, a minute quantity of a metal or its oxide, usually about o.oor $\mathrm{mg}$ in the form of powder, is placed at the center of the platinum strip $P$, the window $M$ screwed down, the cylinder closed and filled with hydrogen, and then the electric circuit is made through P. One observer watches the metallic speck or dust through the microscope and gradually 
increases the current until the melting point is reached, while, simultaneously, another observer reads this temperature with the pyrometer. Only one melt is taken on a given platinum strip.

Temperature Scale.-The Holborn-Kurlbanm pyrometer was calibrated by sighting upon an improved form of the electrically heated experimental black-body due to Lummer and Kurlbaum, the temperature of which was given by the electromotive forces of two platinum, platinum-rhodium thermoelements as measured on a potentiometer. The temperature scale of the thermoelements was obtained by assuming the following melting points: $\mathrm{Zn}=419^{\circ} \circ \mathrm{O}, \mathrm{Sb}=630^{\circ} \cdot 5, \mathrm{C} 11=\mathrm{IO} 84^{\circ} \cdot \mathrm{O}$, all these metals being of "Kahlbaum" purity. As an upper fixed point, the melting point of platinum was taken as $1753^{\circ} \mathrm{C}$, determined from measurements with the optical pyrometer. In the optical pyrometer two lamps were used which gave practically identical values for every temperature observed. As the establishment of the high temperature scale of the Burean of Standards is treated at length elsewliere ${ }^{4}$ in this Bulletin, further discussion of this scale need not be given here.

The indications of the optical pyrometer, when sighted upon platinum through a mica window, are subject to two corrections, one for the reflection and absorption of the mica, the other for the selective emission of the platinum for the light used-in this case, red light $\lambda=0.66 \mu$. The former correction, which is about $\mathrm{I} 5^{\circ}$, is easily determined and checked between measurements of the melting points by taking observations of the platinum brightness at a definite temperature both with and without the mica interposed, with a second mica strip always in place to prevent air currents.

The correction for the selective emission of platinum is discussed in the paper above cited. The magnitude of this correction varies from IIO to $160^{\circ} \mathrm{C}$ and is known to at least $\mathrm{IO}^{\circ}$ within the temperature range here used.

Sources of the Materials.-Chemically pure elements are difficult to get, and it is desirable to use products from different sources and of known analyses. These experiments were greatly facilitated by the willingness of scientists possessing very pure samples to put them at our disposal. 
M. Copaux of Paris, who has recently ${ }^{5}$ completed a most comprehensive study of the properties of cobalt and nickel, and produced these metals containing less than I/200o part impurities, furnished samples of these elements. Dr. H. Goldschmidt of Essen Ruhr, Germany, sent pieces of his pure aluminothermic metals, nannely, chromium and manganese, all of an average purity of 98 to 99 per cent; and Prof. C. F. Burgess of the University of Wisconsin supplied samples of his pure electrolytic iron. The other samples were from Kahlbaum and of "Kahlbaum" grade except as otherwise noted.

\section{IRON.}

Iron from two sources was used, "Kahlbaum" iron in the form of powder, and electrolytic iron in lumps, from Prof. C. F. Burgess, from which particles weighing slightly more than $0.00 \mathrm{I}$ ing were chipped. This electrolytic iron had the following composition, as determined from an analysis of a similar sample by Mr. A. A. Blair, of Wisconsin:

$\begin{array}{lll}\text { Sulphur, none. } & \text { Manganese, none. } \\ \text { Silicon, } \quad \text { O.OI3 per cent. } & \text { Carbon, } \text { o.oI } 2 . \\ \text { Phosphorus, } 0.004 & \text { Hydrogen, } & \text { 0.072. }\end{array}$

Iron as it approaches the melting point becomes plastic, so that the actual temperature of melting is not sharply defined, there being a considerable transition region.

The very considerable variation in the separate melts appears to be due mainly to the influence of size and shape of the particles on the viscosity and surface tension; also lack of homogeneity in chemical constitution of such minute samples may play some rôle, as well as variations in the temperature of adjacent areas of the platinum strip. That the electrolytic iron melts at a slightly higher temperature seems probable. Any impurity likely to be formed in iron will lower its melting or freezing point; but the total impurities in the electrolytic iron here used will not cause a lowering as great as $5^{\circ} \mathrm{C}$.

${ }^{5}$ H. Copaux, Recherches experimentales sur le Cobalt et sur le Nickel, Ann. Chem. et Phys., 6, p. 508; 1905. 
The corrected values found for all the separate melts are given in Table I.

TABLE I. Melting Point of Iron.

\begin{tabular}{|c|c|c|}
\hline \multicolumn{2}{|c|}{ C. F. Burgess } & "Kahlbaum" \\
\hline \multirow{2}{*}{\multicolumn{2}{|c|}{$\begin{array}{l}\text { Electrolytic. } \\
\quad \mathrm{I} 493^{\circ}\end{array}$}} & Powder. \\
\hline & & I $509^{\circ}$ \\
\hline \multicolumn{2}{|l|}{ I519 } & I 494 \\
\hline \multicolumn{2}{|l|}{ I 5 I 8} & I 5 I 2 \\
\hline \multicolumn{2}{|l|}{ I 5 I 2} & 1483 \\
\hline \multicolumn{2}{|l|}{ I 5 I 2} & I 507 \\
\hline \multicolumn{2}{|l|}{ I 5 I4 } & I 49I \\
\hline \multicolumn{3}{|l|}{ I489 } \\
\hline I 508 & Mean & I 499 \\
\hline \multicolumn{3}{|l|}{1508} \\
\hline \multicolumn{3}{|l|}{ I494 } \\
\hline${ }_{5} 0_{7}$ & & \\
\hline
\end{tabular}

Among previous determinations of the melting point of iron have been the following:

$1600^{\circ}$ Roberts Austen, I899.

I $575^{\circ}$ Le Chatelier, I 90 .

I $55^{\circ}$ Osmond.

I $555^{\circ}\left(\mathrm{I} 490^{\circ}\right)$ Tammann, I 904.

The value given by Tammann, ${ }^{6} \mathrm{I} 555^{\circ}$, is that, assuming the nickel point to be $1484^{\circ}$, as determined by Holborn and Wien. ${ }^{7}$ Tammann's value as obtained by extrapolation of his own thermocouple calibration from the gold point $\left(=1064^{\circ}\right)$ would be about $1490^{\circ}$.

COBALT.

Three kinds of cobalt were used: chips from M. Copaux's sample, "Kahlbaum" cobalt, and the metal obtained from Kahlbaum's nickelfree cobalt-carbonate transformed to cobalt-oxide by heating in air, and reduced to metallic cobalt by hydrogen, in place on the platinum strip on which the melt was taken.

${ }^{6}$ Guertler and Tammann, Zs. Anorg. Chem., 45, p. 205 ; 1905.

7 Holborn and Wien, Wied. Ann., 56, p. 360; r895. 
In great contrast to iron, cobalt possesses a very sharp melting point, and the resulting precision is correspondingly increased, showing that the greater deviations in the measurements on iron are not due to the fault of the method nor to its lack of sensitiveness.

TABLE II. Melting Point of Cobalt.

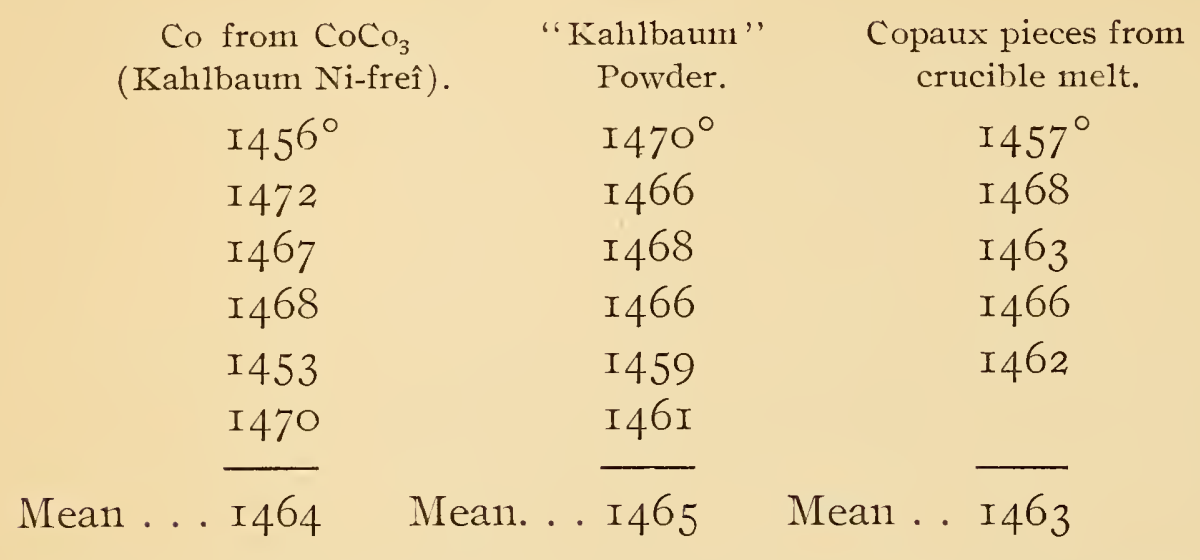

Copanx himself gets $\mathrm{I} 53 \mathrm{O}^{\circ}$ for the cobalt point by interpolation between the gold and platinum points, assuming the latter to be $1780^{\circ}$. Recent measurements ${ }^{8}$ of the platinum point show $1780^{\circ}$ to be high by about $70^{\circ}$ on the thermoconple scale, or by about $30^{\circ}$ on the optical scale, as usually defined in terms of Wien's law. Holborn and Valentiner, ${ }^{9}$ however, have recently obtained $\mathrm{I} 789^{\circ}$ for the melting point of platinum, using Wien's equation, the constants of which were newly determined by comparison with the indications of a gas thermometer up to $1600^{\circ}$ Guertler and Tammann get $1505^{\circ}$ for cobalt on the Holborn and Wien scale, or reduced, as explained in the case of iron, their value for cobalt would be about $1455^{\circ}$ on the thermoelectric scale.

Nickel is usually present in cobalt to at least 2 per cent, causing a proportional lowering of the freezing point ${ }^{10}$ of less than $\mathrm{I}^{\circ} \mathrm{C}$. Iron, even if present in considerable quantities, has a negligible effect on the cobalt melting point. Cobalt is less oxidized in the air at high temperatures than are the other elements of the iron group, and

${ }^{8}$ Harker, Chem. News, 91, p. 62; 1905. Holborn and Henning, Sitzber. Berlin Akad., 12, p. 31 ; 1905. Nernst, Berichte Deut. Phys. Ġes., 4, p. 48; rgo6. Waidner and Burgess, 1. c.

${ }^{9}$ Holborn and Valentiner, Ann. d. Physik, 22, p. I; I907.

${ }^{10}$ Guertler and Tammann, Zs. Anorg. Chem., 42, p. 353; I904. 
cobalt oxide is only slightly soluble in the metal. ${ }^{11}$ These properties, taken together with its very sharp melting point, the insignificant effect of its usual impurities on this temperature, and its relative cheapness as compared with the platinum metals, make cobalt, even of a commercial purity, a desirable metal to use for a fixed point in pyrometric measurements.

\section{NICKEL.}

The melting point of nickel was determined with the pure metallic nickel of M. Copaux and with Kahlbaum's cobalt-free nickel oxide reduced by hydrogen on the platinum strip. The inelting point is about as well defined as that of cobalt.

TABLE III. Melting Point of Nickel.

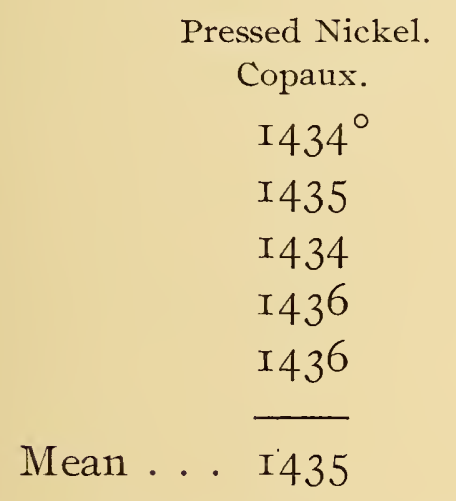

$\mathrm{Ni}$ from the oxide. Kah1baum.

$\mathrm{I} 433^{\circ}$

I 434

I 439

I 434

The preliminary measurements of Dr. Waidner and the author showed that "Kahlbaum" nickel also gave the same value as the above.

The following thermoelectric determinations of the nickel point may be noted:

$$
\begin{aligned}
& \text { I } 420^{\circ} \text { Le Chatelier, I } 887 . \\
& \text { I } 484^{\circ} \text { Holborn and Wien, I } 895 . \\
& \text { I } 427^{\circ} \text { Harker, I905. } \\
& \left(\text { I } 425^{-I} 430^{\circ} \text { ) Tammann, I } 905 .\right. \\
& \text { I } 470^{\circ} \text { Copaux, I905. }
\end{aligned}
$$

The measurements of Copaux and of Holborn and Wien are subject to the same corrections as discussed under cobalt. Le Chatelier's determination is based on a too low value of the gold point. Tam- 
mann's value is that deduced from his own observations as in the case of cobalt and iron. According to the measurements of Waidner and Burgess (1. c.) the optical is $8^{\circ}$ higher than the usual thermoelectric scale at $1427^{\circ}$, so that the nickel freezing point, as determined by Harker using thermocouples, is in exact agreement with the above optical determination.

The presence of cobalt in nickel as impurity will raise the melting point, ${ }^{12}$ while iron as an impurity in nickel will lower its melting point.

\section{CHROMIUM.}

Crystallized chromium from Kahlbaum was used and also Dr. Goldschmidt's aluminothermic chromium of 98-99 per cent purity and carbon free. As Table IV shows, it is about as difficult with chromium as with iron to get a sharp melt. Possibly the greater impurity of the crystallized chromium increases this effect for that sample.

TABLE IV. Melting Point of Chromium.

Chromium crys.
Kahlbaum.
I $5 \mathrm{OI}^{\circ}$
I 472
I 480
I 505
I 475
Mean . . I 487

Cr. 98-99 per cent Goldschmidt.

$\mathrm{I} 497^{\circ}$

$\mathrm{I} 483$

I 486

I 484

I494

A thermoelectric determination of the chrominum melting point has been made by Lewis, ${ }^{13}$ using 99 per cent chromium obtained by the Goldschmidt process. The melt was made in a lime crucible in an oxy-coal-gas flame; two melts gave $5_{5} \mathrm{IO}^{\circ}$ and $\mathrm{I} 52 \mathrm{O}^{\circ}$.

\section{MANGANESE.}

Two samples of manganese were used: "Kahlbaum" manganese, and a sample from Dr. Goldschmidt, 98 per cent manganese, carbon free and technically iron free. The manganese point, although

12 Tammann, 1. c.

${ }^{13}$ E. A. Lewis, Chem. News, 86, p. I3; I902. 
the lowest in the series, is the least satisfactory to determine on account of the very great temperature interval (over $25^{\circ} \mathrm{C}$ ) in which the melt takes place.

TABLE V. Melting Point of Manganese.

$\begin{array}{cc}\text { Manganese } & \text { Mn } 98 \text { per cent } \\ \text { "Kahlbaum." } & \text { Goldschmidt. } \\ \text { I } 226^{\circ} & \text { I } 207^{\circ} \\ \text { I } 203 & \text { I } 2 \text { IO } \\ \text { I I97 } & \\ \text { I I98 } & \end{array}$

Mean . . . I207

First signs of melting were evident as low as II95 $\mathrm{C}$, and the melt of relatively large pieces was not complete at $\mathrm{I} 22 \mathrm{O}^{\circ} \mathrm{C}$.

Heraeus ${ }^{14}$ found $1245^{\circ}$, by observing with a telescope the melt in hydrogen within an electric furnace, whose temperature was given with a thermoelement and pyrometer-galvanometer. Levin and Tammann, ${ }^{15}$ also using a thermoelement, get between $\operatorname{IIgO}^{\circ}$ and I $200^{\circ}$ for the manganese melting point.

\section{CONCLUSION.}

The values found by the radiation method described above, for the melting points, in an atmosphere of hydrogen of the elements of the iron group in contact with platinum, are as follows:

TABLE VI. Approximate Melting Points of the Iron Group.

$\begin{array}{lcl}\quad \text { Metal. } & \text { Melting point. } & \text { Purity. } \\ \text { Iron } & \text { I } 505^{\circ} \mathrm{C} & 99.95 \\ \text { Chromium } & \text { I } 489 & 98-99 \\ \text { Cobalt } & \text { I } 464 & 99.95 \\ \text { Nickel } & \text { I } 435 & 99.95 \\ \text { Manganese } & \text { I } 207 & 98-99\end{array}$

Of these, the cobalt and nickel melting points appear to be correct to within $5^{\circ}$, while the uncertainty of the iron, chromium, and manganese points is probably less than $10^{\circ} \mathrm{C}$. It is not probable

${ }^{14}$ Heraeus, Zs. Elec. Chem., 8, p. I85; 1902.

${ }^{25}$ Levin and Tammann, Zs. Anorg. Chem., 47, p. I36; I905. 
that any of these metals combines with platinum, or alloys with it until the metal is melted at its natural melting point. The fresh melts are all white, changing to the color characteristic of each metal after standing in the air.

It is not claimed that the above numerical values are final, and they are given mainly as an illustration of the possibilities of a - method which may be the only one available in certain cases. The above values are, however, in excellent agreement with certain of the latest determinations by the thermoelectric method, notably Harker's determination of the nickel point, and the determinations of Tammann and his associates for iron, nickel, cobalt, and manganese when these latter results are reduced by extrapolation from the gold point and account is taken of the difference between the thermoelectric and optical scales. ${ }^{16}$ It would be highly desirable to determine the melting point of cobalt with the greatest accuracy for use as a fixed point in pyrometry.

By this radiation method less than o.oor $\mathrm{mg}$ is required for a single observation, making it readily applicable for the relatively exact determination of the melting points of the rarer refractory elements, and it is the only sensitive method yet suggested when the pure element can be obtained only in very small quantities. It is our intention to continue such determinations whenever it is possible to obtain the refractory elements of sufficient purity.

There may be considerable variations in size of the particles to be melted without appreciable change in the apparent melting point. Furthermore, the method gives the same melting point for the pure metal, and for the metal reduced from the pure oxide by hydrogen in the apparatus used, and requires no transfer or handling of the microscopic quantity of the metal so formed.

For the determination of the melting points of those elements having a higher fusing point than platinum, iridium strips may be used and in some cases perhaps carbon; but it is hoped that we may shortly be able to use tungsten strips. Tungsten, as we have found, ${ }^{17}$ appears to have the highest melting point-above $3000^{\circ} \mathrm{C}$ - of any element that can be melted without considerable previous evapora-

\footnotetext{
${ }^{16}$ Waidner and Burgess, this Bulletin, 3, p. I; 1907.

17 Waidner and Burgess: Temperature and selective radiation of incandescent lamps, Electrical World, Nov. Io, I906, p. 915. This Bulletin, 2, p. 319; 1906.
} 
tion, and appears to possess the further advantage of being unattacked by hydrogen. The above apparatus could evidently be arranged, if necessary, to work with a vacuum instead of an atmosphere of hydrogen or other gas.

It might also be possible, as in the case of steels, to apply the method to a determination of carbon or other content from the melting point measurements.

To Mr. J. R. Fehr credit is due for efficient aid in carrying out the above experiments.

Washington, December if, 1906. 